\title{
Expression levels of FBXW7 and MDM2 E3 ubiquitin ligases and their c-Myc and p53 substrates in patients with dysplastic nevi or melanoma
}

\author{
JULIJA MOZURAITIENE ${ }^{1,2}$, ZIVILE GUDLEVICIENE ${ }^{3}$, IEVA VINCERZEVSKIENE ${ }^{4,5}$, \\ AIDA LAURINAVICIENE $^{6,7}$ and JUSTINAS PAMEDYS ${ }^{7}$
}

${ }^{1}$ Outpatient Clinic, National Cancer Institute, LT-08660 Vilnius; ${ }^{2}$ Clinic of Internal Diseases,

Family Medicine and Oncology, Faculty of Medicine, Vilnius University, LT-03101 Vilnius;

${ }^{3}$ Biobank; ${ }^{4}$ Laboratory of Clinical Oncology, National Cancer Institute, LT-08660 Vilnius; ${ }^{5}$ Institute of Biosciences, Vilnius University, LT-10257 Vilnius; ${ }^{6}$ Department of Pathology, Forensic Medicine and Pharmacology, Faculty of Medicine, Vilnius University, LT-03101 Vilnius; ${ }^{7}$ National Center of Pathology

Affiliated to Vilnius University Hospital SantarosKlinikos, LT-08406 Vilnius, Lithuania

Received May 26, 2020; Accepted October 9, 2020

DOI: $10.3892 / \mathrm{ol} .2020 .12298$

\begin{abstract}
E3 ubiquitin ligases are of interest as drug targets due to their involvement in the regulation of the functions and interactions of several proteins. Various E3 ligase complexes are considered oncogenes or tumor suppressors associated with the development of melanoma. These proteins regulate the functions of various signaling pathways and proteins, such as p53 and Notch. The aim of the present study was to determine the expression levels of F-box and WD repeat domain-containing 7 (FBXW7), c-Myc, MDM2 and p53 proteins in samples from patients with dysplastic nevi or melanoma, and to evaluate their association with clinicopathological parameters and prognosis of the disease. Paraffin blocks with postoperative material from 100 patients diagnosed with dysplastic moles or melanoma were used in the present study. Tissue microarrays and immunohistochemistry were used to examine FBXW7, c-Myc, MDM2 and p53 protein expression. The results revealed that there was significantly lower FBXW7 expression in advanced melanoma compared with dysplastic nevus, melanoma in situ and stage pT1 melanoma $(\mathrm{P}<0.001)$. Additionally, there was a statistically significant association between the expression levels of FBXW7 and the morphological type of the tumor $(\mathrm{P}<0.001)$. In addition, there was a strong positive association between FBXW7 expression and the changes in c-Myc expression $(\mathrm{P}<0.02)$, and a strong trend was observed between decreased FBXW7 expression and a higher risk of death in patients,
\end{abstract}

Correspondence to: Dr Julija Mozuraitiene, Outpatient Clinic, National Cancer Institute, 1 Santariskiu, LT-08660 Vilnius, Lithuania E-mail: julija.mozuraitiene@nvi.lt

Key words: melanoma, F-box and WD repeat domain-containing 7, p53, c-Myc, MDM2, ubiquitin ligases, prognostic factor with the major factor in patient mortality being the stages of melanoma. Additionally, p53 expression was associated with the depth of melanoma invasion and the morphological type of the tumor. In summary, FBXW7 expression exhibited the highest statistically significant prognostic value and associations with advanced melanoma. As the majority of FBXW7 substrates are oncoproteins, their degradation by FBXW7 may highlight these proteins as potential targets for the treatment of melanoma.

\section{Introduction}

E3 ligases of the ubiquitin proteasome system are involved in the regulation of protein functions, stability and degradation; some of the components of the E3 ligase complexes are considered oncogenes or tumor suppressors with regards to the development of melanoma $(1,2)$. Previous studies have focused on identifying gene products whose expression is altered as a disease progresses, as these may be novel molecular targets for the treatment of melanoma or new prognostic markers to track the course of the disease $(1,3)$.

F-box and WD repeat domain-containing 7 (FBXW7) is a well-studied F-box-containing protein (4-6). F-box proteins are subunits of SCF-type E3 ligases that recognize the substrate, bind to it and target it for ubiquitination and degradation (4). It has been demonstrated that FBXW7 can act as a tumor suppressor by negatively regulating the expression levels of several protein oncogenes, including c-Myc, Notch, cyclin $\mathrm{E}$ and c-Jun (5-8). In melanoma, FBXW7 acts as a tumor suppressor. Studies have revealed that FBXW7 expression is significantly decreased in primary and metastatic melanoma samples compared with samples of dysplastic nevi, and that this decreased FBXW7 expression is associated with melanoma progression $(5,9)$. However, the mechanism underlying the decrease in FBXW7 expression in tumors remains unclear.

One of the most important regulators of FBXW7 is p53 $(10,11)$. p53 is a major tumor suppressor protein, with 
mutations detected in several types of human cancer, such as breast cancer, bone and soft tissue sarcoma, brain tumor, adrenocortical carcinoma, leukemia, stomach cancer and colorectal cancer (12-17). Mao et al (11) revealed that FBXW7 mediates the critical role of p53 in responding to DNA damage, suggesting that FBXW7 may be a p53-dependent gene tumor suppressor involved in tumor development. Further studies have demonstrated that FBXW7 expression may be restored by targeting the p53 signaling pathway $(10,11)$.

c-Myc is a protein that is found in $\sim 70 \%$ of all types of human cancer, including leukemia $(18,19)$, sarcoma $(20)$ and hepatocellular carcinoma $(21,22)$. c-Myc is important for normal cell growth, and cellular Myc protein levels are tightly controlled $(23,24)$. At least four different ubiquitin ligase complexes can target c-Myc for proteasomal degradation, including FBXW7 (23). Previous studies have revealed increased c-Myc expression in advanced and metastatic melanoma (25-29).

The E3 ubiquitin ligase MDM2 is a major negative regulator of the $\mathrm{p} 53$ tumor suppressor protein, and by suppressing p53, MDM2 promotes tumor development (30). In normal cells, the presence of MDM2 is essential for maintaining p53 protein expression at a basal level by regulating its ubiquitination and degradation in the $26 \mathrm{~S}$ proteasome $(31,32)$. In addition, MDM2 suppresses p53 function by directly binding to the transcriptional binding site of $\mathrm{p} 53$, thereby preventing its interaction with transcription factors (33-35). p53 and MDM2 interact and form a negative autoregulation loop in which elevated p53 transcriptional levels activate MDM2, which in turn decrease p53 levels $(15,30,36)$.

The aim of the present study was to determine the protein expression levels of FBXW7, c-Myc, MDM2 and p53 in patients with dysplastic nevi or melanoma using tissue samples. Additionally, the associations between the expression levels of these proteins with clinicopathological parameters and prognosis of the disease were evaluated to determine whether these proteins may be used as prognostic factors for patients with melanoma, potentially allowing for improved modeling of effective personalized treatment of melanoma.

\section{Materials and methods}

Study population. The present study was performed on tissue microarray (TMA) sections obtained from paraffin blocks of postoperative material from 100 patients with dysplastic nevi or skin melanoma treated at the National Cancer Institute (Vilnius, Lithuania) between January 2013 and December 2018. Histological and immunohistochemical analysis was performed at the National Center of Pathology affiliated to Vilnius University Hospital SantarosKlinikos (Vilnius, Lithuania). The present study was approved by the Vilnius Regional Committee of Biomedical Research (approval no. 158200-16-878-387; approval date, 2016-12-13).

The present study included patients $>18$ years old with surgically removed and histologically confirmed dysplastic nevi or melanoma. The present study included 16 patients diagnosed with dysplastic nevi, 16 with in situ melanoma, 17 with pathological tumor (pT) 1 stage, 17 with pT2 stage, 17 with pT3 stage and 17 with pT4 stage melanoma. The following clinicopathological parameters of patients were evaluated:
Sex, age, pT stage (37), morphological tumor type, ulceration and localization. Of the 100 cases under analysis, 39 were male and 61 were female, with a median age of 61 years (range, 21-92 years).

Immunohistochemical (IHC) analysis. The TMAs were constructed from $10 \%$ buffered formalin-fixed (at room temperature for $\sim 24 \mathrm{~h}$ ) paraffin-embedded tissue blocks; 2-mm diameter cores were punctured from the tumor block as randomly selected by a pathologist (1 core per patient), thus producing 2 TMAs constructed using the tissue arraying instrument (TMA Master; 3DHISTECH, Ltd.). The TMA blocks for immunohistochemistry were cut into $2-\mu \mathrm{m}$-thick sections and mounted on TOMO adhesion glass slides (Matsunami Glass Ind., Ltd.). The sections were deparaffinized and rehydrated in a descending alcohol series, and antigen retrieval for antibodies against p53 and c-Myc proteins was performed using DAKO PTLink system with EnVision FLEX Target buffer $\left(\mathrm{pH} \mathrm{8.0)}\right.$ at $95^{\circ} \mathrm{C}$ for $20 \mathrm{~min}$ (both from Dako; Agilent Technologies, Inc.), while that for antibodies against FBXW7 and MDM2 proteins was performed using a Ventana Benchmark Ultra system with Cell Conditioning solution $(\mathrm{pH} 8.5)$ at $100^{\circ} \mathrm{C}$ for $36 \mathrm{~min}$. (both from Ventana Medical Systems, Inc.; Roche Diagnostics). The sections were blocked with FLEX Peroxide Block (cat. no. SM801; Dako; Agilent Technologies, Inc.) at room temperature for $5 \mathrm{~min}$ for p53, $10 \mathrm{~min}$ for c-Myc and $8 \mathrm{~min}$ for FBXW7 and MDM2.Subsequently, the sections were incubated with antibodies against p53 (1:200; cat. no. M7001, clone DO-7; Dako; Agilent Technologies, Inc.) and c-Myc (1:40; cat. no. ab32072, cloneY69; Abcam) at room temperature for $30 \mathrm{~min}$, then incubated using a DAKO EnVision FLEX system (Dako; Agilent Technologies, Inc.) for $20 \mathrm{~min}$ at room temperature. Incubation with antibodies against FBXW7 (1:50; cat. no. MA5-26562, clone OTI6F5; Thermo Fisher Scientific, Inc.) and MDM2 (1:250; cat. no. MA1-113, clone IF2; Invitrogen; Thermo Fisher Scientific, Inc.) was performed at $37^{\circ} \mathrm{C}$ for $32 \mathrm{~min}$ and then using the VentanaUltraview DAB detection kit (Ventana Medical Systems, Inc.; Roche Diagnostics) for $8 \mathrm{~min}$ at $37^{\circ} \mathrm{C}$. Finally, the sections were developed using DAB, counterstained using Mayer's hematoxylin at room temperature for $10 \mathrm{~min}$ and mounted. Negative controls were performed by omitting the application of the primary antibody. The IHC slides were observed using a light microscope at a magnification of x20 (0.5 $\mu \mathrm{m}$ resolution) using a bright field AperioScanScope XT Slide Scanner (Leica Microsystems, Inc.).

Assessment of FBXW7, c-Myc, MDM2 and p53 expression. The pathologist performed a visual assessment of staining intensity and overall percentage of cells staining. The intensity of protein immunostaining was scored as 0-3: 0, Negative staining; 1 , weak staining; 2 , moderate staining; and 3 , strong staining. The percentage of nuclear staining was graded in 4 categories: $1,0-25 \% ; 2,26-50 \% ; 3,51-75 \%$; and 4, 76-100\%. The combined score obtained by multiplying the staining intensity score with the staining percentage score was graded as follows: 0-6, Low expression; and 7-12, high expression.

Statistical analysis. Statistical analysis was performed using STATA v11.2 (StataCorp LP). Fisher's exact test was used to 


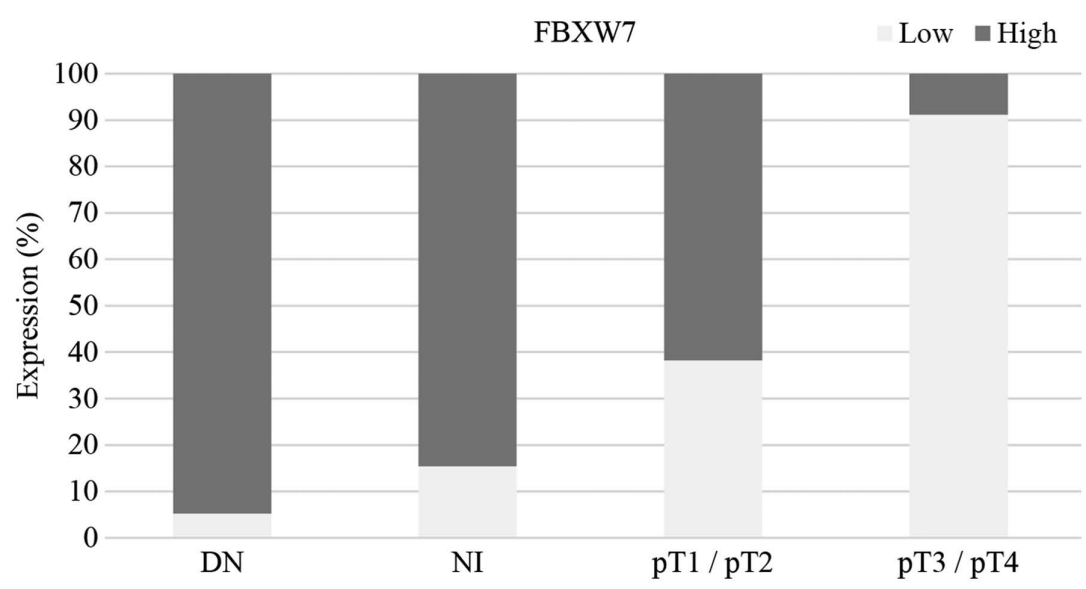

Figure 1. Low FBXW7 expression is associated with melanoma progression. DN, dysplastic nevi; NI, non-invasive melanoma/melanoma in situ; FBXW7, F-box and WD repeat domain-containing 7; pT, pathological tumor stage.

evaluate the association between protein expression and the patient clinicopathological parameters. Univariate and multivariate Cox proportional and hazard regression analyses were performed to estimate the crude hazard ratios (HRs), adjusted HRs and $95 \%$ confidence intervals (CIs) of HRs. P<0.05 was considered to indicate a statistically significant difference.

\section{Results}

Patient characteristics. Based on the morphological type of melanoma, there were 48 cases of superficial melanoma, 27 cases of nodular melanoma and 9 cases of lentigomaligna. Of all the melanoma cases analyzed, 26 had melanoma depths of $\leq 1 \mathrm{~mm}$ and 42 cases had depths of invasion $>1 \mathrm{~mm}$, while 32 cases were non-invasive. Of the 68 melanoma cases ranging from pathological stages pT1-pT4, 22 were ulcerated. In $77 \%$ of the cases, the tumor was diagnosed in sun-exposed areas (Table I).

FBXW7 expression is associated with pathological stage, melanoma invasion depth and tumor morphological type. High FBXW7 expression was observed in 53\% of samples, and low expression was observed in $47 \%$ of cases (Table I). There was a significant association between FBXW7 expression and pT stage. There was a significantly lower level of FBXW7 expression in advanced melanoma (pT3/pT4) compared with dysplastic nevi, melanoma in situ and $\mathrm{pT} 1 / \mathrm{pT} 2$ stage melanoma $(\mathrm{P}<0.001$; Fisher's exact test; Table I). Fig. 1 shows the proportion of high/low FBXW7 expression in dysplastic nevi, melanoma in situ, pT1/pT2 and pT3/pT4 melanoma. Fig. 2 shows the changes of immunostaining of FBXW7 protein depending on pT stage (pT1-pT4). There was strong FBXW7 immunostaining in pT1 melanoma, moderate staining in pT2, weak staining in pT3 and negative staining in pT4 melanoma (Fig. 2).

Additionally, there was a statistically significant association between FBXW7 expression and the morphological type of the tumor $(\mathrm{P}<0.001)$; high FBXW7 expression was observed in $93.7 \%$ of dysplastic nevus tissues, $77.8 \%$ of lentigomaligna cases and $54.2 \%$ of cases of superficial spreading melanoma, whereas $81.5 \%$ of nodular melanomas exhibited low FBXW7 expression (Table I). Furthermore, there was a statistically significant association between FBXW7 expression and the tumor invasion $(\mathrm{P}<0.001)$, with a depth $\leq 1 \mathrm{~mm}$ observed in $76.9 \%$ of cases with high FBXW7 expression, whereas $90.5 \%$ of cases with melanoma invasion $>1 \mathrm{~mm}$ exhibited low FBXW7 expression (Table I). There was no statistically significant association between FBXW7 expression and sex, age or tumor localization (Table I).

p53 expression is associated with the depth of melanoma invasion and the morphological type of the tumor. There was no statistically significant association between $\mathrm{p} 53$ expression and melanoma pT stage. Almost equal proportions of high and low expression levels of p53 were observed in dysplastic nevi and melanoma in situ. Higher proportions of high p53 expression were observed in stage $\mathrm{pT} 1 / \mathrm{pT} 2$ and $\mathrm{pT} 3 / \mathrm{pT} 4$ melanoma samples compared with high p53 expression in dysplastic nevi and melanoma in situ tissues (Fig. 3). High p53 expression was observed in $70-80 \%$ of melanoma samples ranging from stage $\mathrm{pT} 1$ to pT4, but p53 expression was not associated with pT stage $(\mathrm{P}=0.06$; Table II). Fig. 4 shows the immunostaining of p53 protein in different pT melanoma stages (pT1-pT4). Additionally, there was no association between p53 expression with sex, age and tumor localization.

There was a statistically significant association between $\mathrm{p} 53$ expression and depth of melanoma invasion $(\mathrm{P}=0.02)$; when melanoma depth was $\leq 1$ and $>1 \mathrm{~mm}$, high p53 expression was observed in 76.9 and $76.2 \%$ of cases, respectively, whereas a low p53 protein expression was detected in $53.1 \%$ of non-invasive tumors (Table II). There was also a statistically significant association between p53 expression and the morphological type of the tumor $(\mathrm{P}=0.01)$, with high $\mathrm{p} 53$ expression observed in $85.2 \%$ of nodular melanomas and in $68.8 \%$ of superficial spreading melanomas, while p53 expression in lentigomaligna tissues was mainly low (Table II).

c-Myc protein expression is not associated with advanced melanoma. Examination of c-Myc protein expression (Fig. 5) revealed that its expression was high in $36 \%$ of cases and low in $64 \%$ of cases. c-Myc protein expression was not significantly associated with advanced melanoma. Similarly, c-Myc expression was not associated with any clinicopathological parameters, including sex, age, morphological type of the tumor, depth of invasion and localization (Table III). 
Table I. Association between FBXW7 protein expression and clinicopathological variables.

\begin{tabular}{|c|c|c|c|c|}
\hline \multirow{2}{*}{$\begin{array}{l}\text { Clinicopathological } \\
\text { variables }\end{array}$} & \multirow[b]{2}{*}{$\mathrm{N}$} & \multicolumn{2}{|c|}{$\begin{array}{c}\text { FBXW7 expression, } \\
\text { n (\%) }\end{array}$} & \multirow[b]{2}{*}{ P-value } \\
\hline & & High & Low & \\
\hline All cases & 100 & $53(53.0)$ & $47(47.0)$ & - \\
\hline Sex & & & & 0.41 \\
\hline Male & 39 & $23(54.8)$ & $16(45.2)$ & \\
\hline Female & 61 & $30(49.2)$ & $31(50.8)$ & \\
\hline Age, years & & & & 0.69 \\
\hline$\leq 58$ & 44 & $25(56.8)$ & $19(43.2)$ & \\
\hline$>58$ & 56 & $28(50.0)$ & $28(50.0)$ & \\
\hline pT stage & & & & $0.001^{\mathrm{a}}$ \\
\hline Dysplastic nevi & 16 & $15(93.7)$ & $1(6.25)$ & \\
\hline pTis & 16 & $14(73.7)$ & $2(12.5)$ & \\
\hline pT1 & 17 & $15(88.2)$ & $2(11.8)$ & \\
\hline pT2 & 17 & $6(35.3)$ & $11(64.7)$ & \\
\hline pT3 & 17 & $1(5.9)$ & $16(94.1)$ & \\
\hline pT4 & 17 & $2(11.8)$ & $15(88.2)$ & \\
\hline Depth of invasion, mm & & & & $0.001^{\mathrm{a}}$ \\
\hline$\leq 1$ & 26 & $20(76.9)$ & $6(23.1)$ & \\
\hline$>1$ & 42 & $4(9.5)$ & $38(90.5)$ & \\
\hline Non-invasive & 32 & $29(90.6)$ & $3(9.4)$ & \\
\hline Morphology & & & & $0.001^{\mathrm{a}}$ \\
\hline Superficial spreading & 48 & $26(54.2)$ & $22(45.8)$ & \\
\hline Lentigomaligna & 9 & $7(77.8)$ & $2(22.2)$ & \\
\hline Nodular & 27 & $5(18.5)$ & $22(81.5)$ & \\
\hline Dysplastic nevi & 16 & $15(93.7)$ & $1(6.5)$ & \\
\hline Site & & & & 0.54 \\
\hline Sun-protected & 13 & $5(38.5)$ & $8(61.5)$ & \\
\hline Sun-exposed & 77 & $42(54.5)$ & $35(45.5)$ & \\
\hline Unknown & 10 & $6(60.0)$ & $4(4.0)$ & \\
\hline $\begin{array}{l}\text { Ulceration in melanoma } \\
\text { (pT1-pT4) }\end{array}$ & 68 & & & 0.18 \\
\hline Present & 22 & $5(22.7)$ & $17(77.3)$ & \\
\hline Absent & 46 & $19(41.3)$ & $27(58.7)$ & \\
\hline
\end{tabular}

${ }^{\mathrm{a}} \mathrm{P}<0.001$. pT, pathological tumor; FBXW7, F-box and WD repeat domain-containing 7.

Decreased c-Myc expression was observed in $56 \%$ of melanoma cases, and in $71.4 \%$ of these cases, decreased expression was observed at melanoma depths $>1 \mathrm{~mm}$. There were no changes in c-Myc expression in dysplastic nevus, as both increased and decreased expression was observed in $50 \%$ of cases. There was a slight decrease in c-Myc expression observed in cases with melanoma in situ and stage pT1 melanoma, and low c-Myc protein expression levels were observed in $70.6 \%$ of melanoma cases in stages pT2, pT3 and pT4. However, there was no statistically significant association between c-Myc expression levels and the pathological stage of melanoma $(\mathrm{P}=0.75)$.
Table II. Association between p53 protein expression and clinicopathological variables.

\begin{tabular}{|c|c|c|c|c|}
\hline \multirow{2}{*}{$\begin{array}{l}\text { Clinicopathological } \\
\text { variables }\end{array}$} & \multirow[b]{2}{*}{$\mathrm{N}$} & \multicolumn{2}{|c|}{$\begin{array}{c}\text { p53 expression, } \\
\text { n }(\%)\end{array}$} & \multirow[b]{2}{*}{ P-value } \\
\hline & & High & Low & \\
\hline All cases & 100 & $53(53.0)$ & $47(47.0)$ & - \\
\hline Sex & & & & 0.20 \\
\hline Male & 39 & $23(59.0)$ & $16(41.0)$ & \\
\hline Female & 61 & $44(72.1)$ & 17 (27.9) & \\
\hline Age, years & & & & 0.52 \\
\hline$\leq 58$ & 44 & $31(70.5)$ & $13(29.5)$ & \\
\hline$>58$ & 56 & $36(64.3)$ & $20(35.7)$ & \\
\hline pT stage & & & & 0.06 \\
\hline Dysplastic nevi & 16 & $8(50.0)$ & $8(50.0)$ & \\
\hline pTis & 16 & $7(43.7)$ & $9(56.3)$ & \\
\hline pT1 & 17 & $14(82.3)$ & $3(17.7)$ & \\
\hline pT2 & 17 & $12(70.6)$ & $5(29.4)$ & \\
\hline pT3 & 17 & $12(70.6)$ & $5(29.4)$ & \\
\hline pT4 & 17 & $14(82.3)$ & $3(17.7)$ & \\
\hline Depth of invasion, mm & & & & $0.02^{\mathrm{a}}$ \\
\hline$\leq 1$ & 26 & $20(76.9)$ & $6(23.1)$ & \\
\hline$>1$ & 42 & $32(76.2)$ & $10(23.8)$ & \\
\hline Non-invasive & 32 & $15(46.9)$ & $17(53.1)$ & \\
\hline Morphology & & & & $0.01^{\mathrm{a}}$ \\
\hline Superficial spreading & 48 & $33(68.8)$ & $15(31.2)$ & \\
\hline Lentigomaligna & 9 & $3(33.3)$ & $6(66.7)$ & \\
\hline Nodular & 27 & $23(85.2)$ & $4(14.8)$ & \\
\hline Dysplastic nevi & 16 & $8(50.0)$ & $8(50.0)$ & \\
\hline Site & & & & 0.35 \\
\hline Sun-protected & 13 & 11 (84.6) & $2(15.4)$ & \\
\hline Sun-exposed & 77 & 49 (63.6) & $28(36.4)$ & \\
\hline Unknown & 10 & $7(70.0)$ & $3(30.0)$ & \\
\hline
\end{tabular}

${ }^{\mathrm{a}} \mathrm{P}<0.02$. pT, pathological tumor.

MDM2 expression levels are not associated with advanced melanoma. The present study revealed that there was low MDM2 expression in $97 \%$ of all investigated tumor samples; therefore, MDM2 expression did not exhibit any statistically significant association with advanced melanoma or any other clinicopathological parameters (Table IV and Fig. 6).

FBXW7 protein expression is associated with $c-M y c$ protein expression. Fisher's exact test was performed to evaluate the association between FBXW7, c-Myc, MDM2 and p53 expression. The results revealed that there was a statistically significant association between FBXW7 and c-Myc expression, revealing that $76.6 \%$ of cases with low FBXW7 expression had also low c-Myc expression ( $\mathrm{P}=0.02$; Table $\mathrm{V}$ ). There was no other statistically significant association between protein expression.

High FBXW7 expression is positively associated with survival. A univariate Cox regression analysis was used to determine 
A
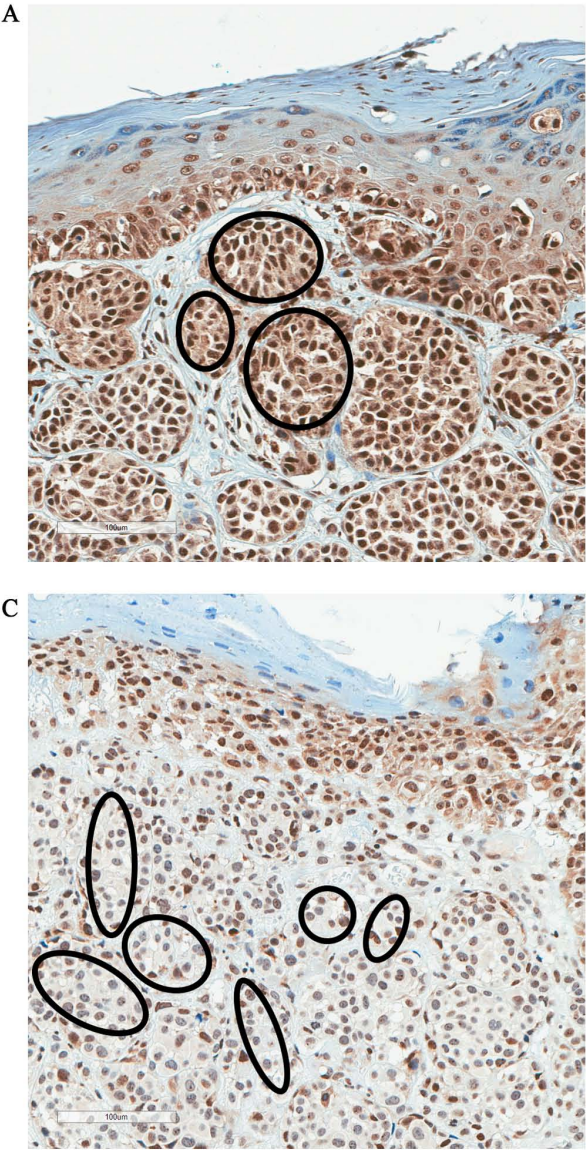
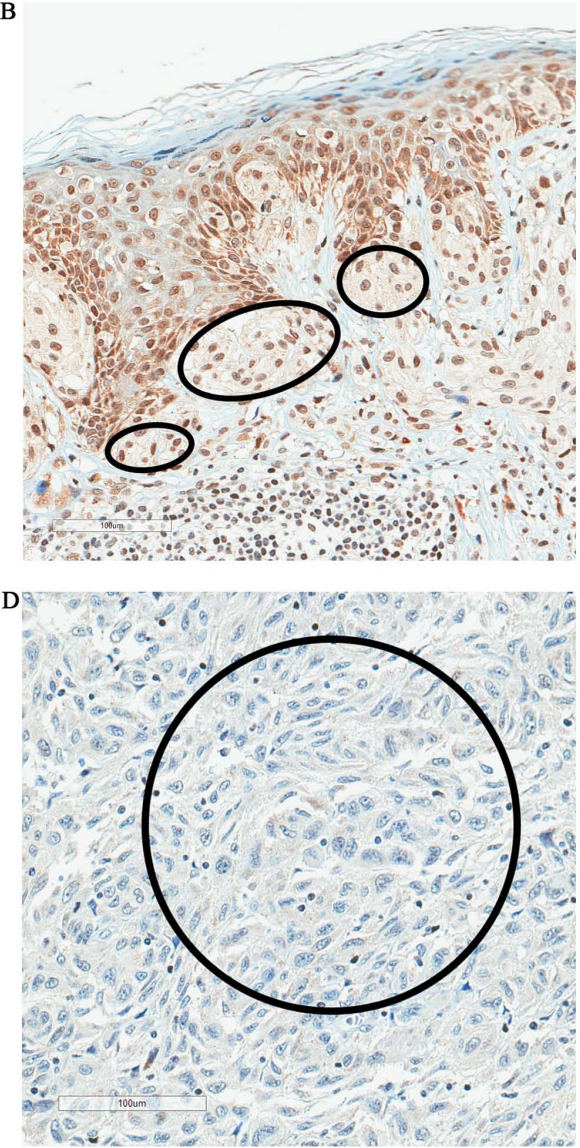

Figure 2. FBXW7 protein expression in cutaneous melanoma. Representative images of (A) strong FBXW7 immunostaining in pT1 melanoma, (B) moderate FBXW7 immunostaining in pT2 melanoma, (C) weak FBXW7 staining in pT3 melanoma and (D) negative FBXW7 staining in pT4 melanoma. Marked areas indicate FBXW7 staining in malignant melanocytes. Magnification, x100. FBXW7, F-box and WD repeat domain-containing 7; pT, pathological tumor stage.

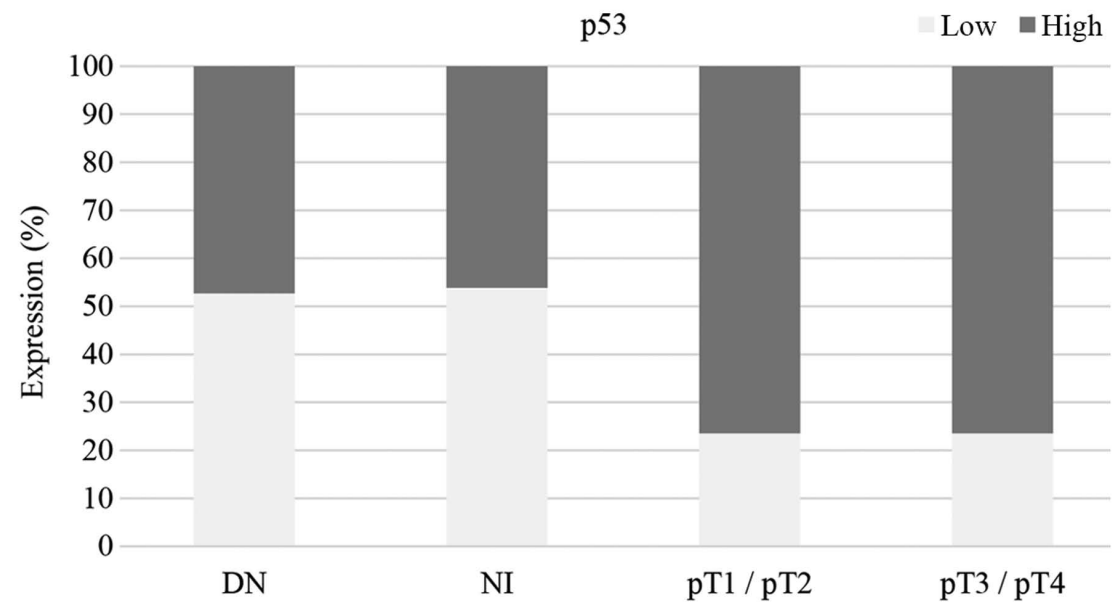

Figure 3. p53 expression in DN, NI, pT1/pT2 and pT3/pT4 melanoma. DN, dysplastic nevi; NI, non-invasive melanoma/melanoma in situ; pT, pathological tumor stage.

which of the analyzed clinicopathological indicators may be associated with survival. The results revealed that sex, age, morphological type and the localization of tumors were not significantly associated with mortality. However, tumor ulceration was found to increase the risk of death by 2.79 times, although this rate was not statistically significant $(\mathrm{P}=0.06)$. Patient survival was significantly influenced by pT stage, where the risk of death increased by 5.6 times with advanced stage $(\mathrm{P}=0.03)$. Taking into account the impact of changes in the expression levels of FBXW7, c-Myc and p53 on the risk of death, the results revealed that high FBXW7 expression decreased the risk of death and improved survival $(\mathrm{P}=0.08)$, and high expression levels of p53 increased the risk of death by 2.48 times $(\mathrm{P}=0.10)$. However, these rates were not statistically significant. The results revealed that c-Myc expression was not significantly associated with mortality (Table VI). A multivariate Cox regression analysis revealed no statistically significant results (Table VII). 

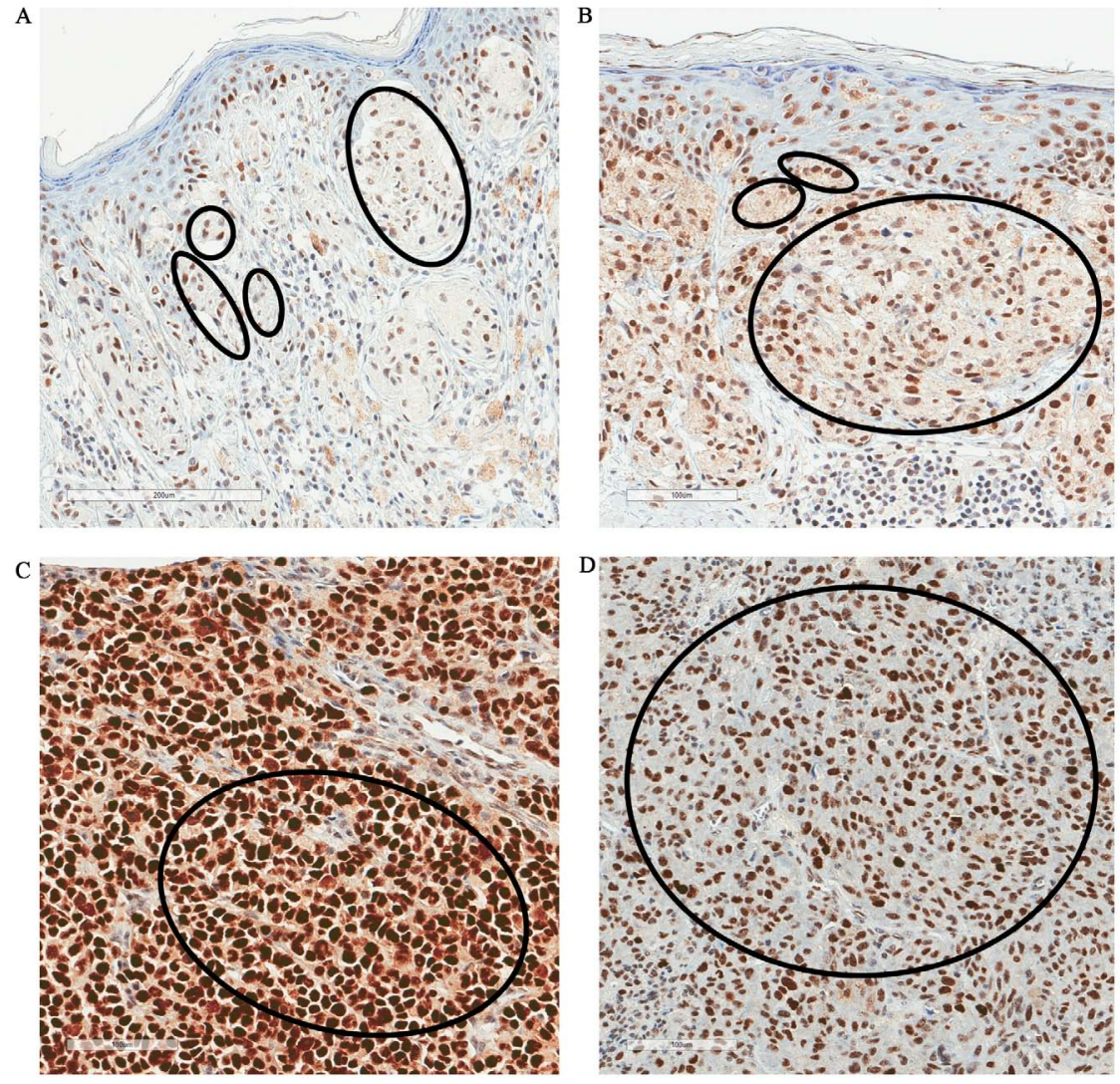

Figure 4. p53 protein expression in cutaneous melanoma. Representative images of (A) moderate p53 immunostaining in pT1 melanoma and (B) in pT2 melanoma, and (C) strong p53 immunostaining in pT3 and (D) in pT4 melanoma. Marked areas indicate p53 staining in malignant melanocytes. Magnification, $\mathrm{x} 100$. pT, pathological tumor stage.

A

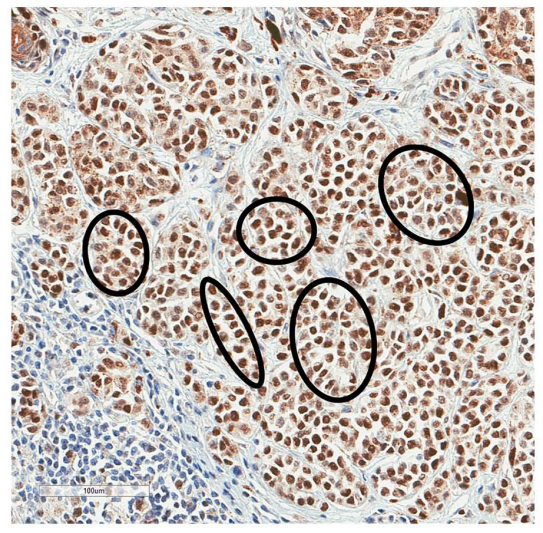

C

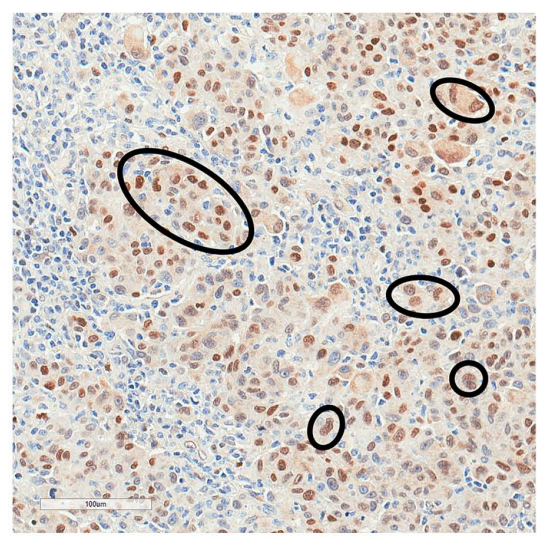

B

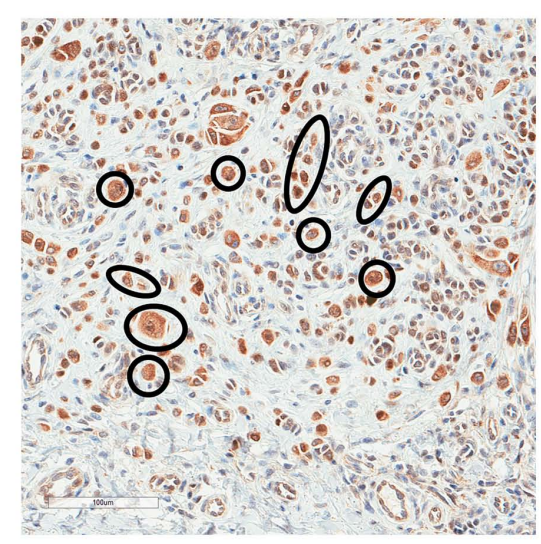

D

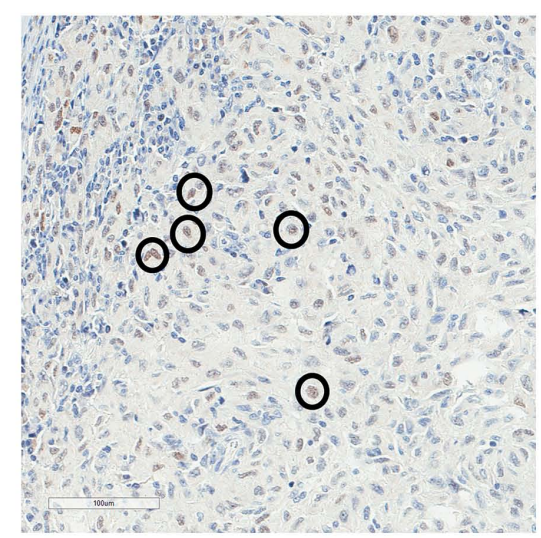

Figure 5. c-Myc protein expression in cutaneous melanoma. Representative images of (A) high c-Mycimmunostaining in pT1 melanoma, (B) moderate c-Mycimmunostainingin pT2 melanoma and (C) in pT3 melanoma, and (D) weak c-Mycimmunostaining in pT4 melanoma. Marked areas indicate c-Myc staining in malignant melanocytes. Magnification, x100. pT, pathological tumor stage. 
Table III. Association between c-Myc protein expression and clinicopathological variables.

\begin{tabular}{|c|c|c|c|c|}
\hline \multirow{2}{*}{$\begin{array}{l}\text { Clinicopathological } \\
\text { variables }\end{array}$} & \multirow[b]{2}{*}{$\mathrm{N}$} & \multicolumn{2}{|c|}{$\begin{array}{c}\text { c-Myc expression, } \\
\mathrm{n}(\%)\end{array}$} & \multirow[b]{2}{*}{ P-value } \\
\hline & & High & Low & \\
\hline All cases & 100 & $36(36.0)$ & $64(64.0)$ & - \\
\hline Sex & & & & 0.29 \\
\hline Male & 39 & $17(43.6)$ & $22(56.4)$ & \\
\hline Female & 61 & $19(31.1)$ & $42(68.9)$ & \\
\hline Age, years & & & & 0.53 \\
\hline$\leq 58$ & 44 & $14(31.8)$ & $30(68.2)$ & \\
\hline$>58$ & 56 & $22(39.3)$ & $34(60.7)$ & \\
\hline pT stage & & & & 0.75 \\
\hline Dysplastic nevus & 16 & $8(50.0)$ & $8(50.0)$ & \\
\hline pTis & 16 & $6(37.5)$ & $10(62.5)$ & \\
\hline pT1 & 17 & $7(41.2)$ & $10(58.8)$ & \\
\hline pT2 & 17 & $5(29.4)$ & $12(70.6)$ & \\
\hline pT3 & 17 & $5(29.4)$ & $12(70.6)$ & \\
\hline pT4 & 17 & $5(29.4)$ & $12(70.6)$ & \\
\hline Depth of invasion, $\mathrm{mm}$ & & & & 0.37 \\
\hline$\leq 1$ & 26 & $10(38.5)$ & $16(61.5)$ & \\
\hline$>1$ & 42 & $12(28.6)$ & $30(71.4)$ & \\
\hline Non-invasive & 32 & $14(43.7)$ & $18(56.3)$ & \\
\hline Morphology & & & & 0.57 \\
\hline Superficial spreading & 48 & $17(35.4)$ & $31(64.6)$ & \\
\hline Lentigomaligna & 9 & $3(33.3)$ & $6(66.7)$ & \\
\hline Nodular & 27 & 8 (29.6) & $19(70.4)$ & \\
\hline Dysplastic nevus & 16 & $8(50.0)$ & $8(50.0)$ & \\
\hline Site & & & & 0.59 \\
\hline Sun-protected & 13 & $5(38.5)$ & $8(61.5)$ & \\
\hline Sun-exposed & 77 & $29(37.7)$ & $48(62.3)$ & \\
\hline Unknown & 10 & $2(20.0)$ & $8(80.0)$ & \\
\hline
\end{tabular}

pT, pathological tumor.

\section{Discussion}

FBXW7 is a tumor suppressor that controls the protein expression levels of several oncogenes, including c-Myc, Notch, Cyclin E, c-Jun, Mcl-1 and m-TOR $(5,38,39)$. However, little is known regarding the regulation of FBXW7 in tumors. Regulation of FBXW7 expression may occur at the transcriptional or protein levels, as well as by post-translational modifications, such as phosphorylation (40). p53 molecules, NUMB4, NF- $\kappa$ B1, microRNA-27 and microRNA-223 are known to be important in FBXW7 regulation (10).

Previous studies have revealed decreased FBXW7 activity in melanoma cells $(3,9)$. The present study demonstrated that FBXW7 expression was lower in primary melanoma compared with dysplastic nevi. FBXW7 expression in metastatic melanoma was lower compared with in primary melanoma, and its decreased expression was associated with a less favorable 5 -year survival rate (9). Furthermore, in vitro experiments
Table IV. Association between MDM2 protein expression and clinicopathological variables.

\begin{tabular}{|c|c|c|c|c|}
\hline \multirow{2}{*}{$\begin{array}{l}\text { Clinicopathological } \\
\text { variables }\end{array}$} & \multirow[b]{2}{*}{$\mathrm{N}$} & \multicolumn{2}{|c|}{$\begin{array}{l}\text { MDM2 expression, } \\
\mathrm{n}(\%)\end{array}$} & \multirow[b]{2}{*}{ P-value } \\
\hline & & High & Low & \\
\hline All cases & 100 & $3(3.0)$ & $97(97.0)$ & - \\
\hline Sex & & & & 0.56 \\
\hline Male & 39 & $2(5.1)$ & $37(94.9)$ & \\
\hline Female & 61 & $1(1.1)$ & $60(98.9)$ & \\
\hline Age, years & & & & 0.58 \\
\hline$\leq 58$ & 44 & $2(4.5)$ & $42(95.5)$ & \\
\hline$>58$ & 56 & $1(1.8)$ & $55(98.2)$ & \\
\hline pT stage & & & & 0.99 \\
\hline Dysplastic nevus & 16 & $0(0.0)$ & $16(100.0)$ & \\
\hline pTis & 16 & $1(6.3)$ & $15(93.7)$ & \\
\hline pT1 & 17 & $1(5.9)$ & $16(94.1)$ & \\
\hline pT2 & 17 & $0(0.0)$ & $17(100.0)$ & \\
\hline pT3 & 17 & $1(5.9)$ & $16(94.1)$ & \\
\hline pT4 & 17 & $0(0.0)$ & $17(100.0)$ & \\
\hline Depth of invasion, $\mathrm{mm}$ & & & & 0.99 \\
\hline$\leq 1$ & 26 & $1(3.8)$ & $25(96.2)$ & \\
\hline$>1$ & 42 & $1(2.4)$ & $41(97.6)$ & \\
\hline Non-invasive & 32 & $1(3.1)$ & $31(96.9)$ & \\
\hline Morphology & & & & 0.34 \\
\hline Superficial spreading & 48 & $1(2.1)$ & $47(97.9)$ & \\
\hline Lentigomaligna & 9 & $1(11.1)$ & $8(88.9)$ & \\
\hline Nodular & 27 & $1(3.7)$ & $26(96.3)$ & \\
\hline Dysplastic nevus & 16 & $0(0.0)$ & $16(100.0)$ & \\
\hline Site & & & & 0.99 \\
\hline Sun-protected & 13 & $0(0.0)$ & $13(100.0)$ & \\
\hline Sun-exposed & 77 & $3(3.9)$ & $74(96.1)$ & \\
\hline Unknown & 10 & $0(0.0)$ & $10(100.0)$ & \\
\hline
\end{tabular}

pT, pathological tumor.

have demonstrated that FBXW7 suppresses the migration of melanoma cells via the MAPK/ERK signaling pathway; therefore, suppression of FBXW7 in melanoma cells results in increased cell migration and stress fiber formation (9).

The results of the present study revealed that FBXW7 expression decreased in advanced melanoma, and a statistically significant association was found between the decrease in FBXW7 expression and the increasing pT stage of melanoma. Additionally, a trend was observed between decreased FBXW7 expression and an increased risk of death in patients, although this association was not significant.

Previous studies have demonstrated that decreased FBXW7 expression is associated with melanoma progression and the accumulation of c-Myc protein $(3,9,41)$. c-Myc is one of the major targets of FBXW7, and c-Myc regulates the expression of $>15 \%$ of the genes involved in processes of cell differentiation, proliferation, protein synthesis, metabolism and apoptosis; thus, impaired c-Myc function may underlie 
Table V. Association between the changes in the protein expression levels of FBXW7, c-Myc, MDM2 and p53.

\begin{tabular}{|c|c|c|c|c|c|c|c|c|c|c|}
\hline \multirow[b]{2}{*}{ Proteins } & \multirow[b]{2}{*}{ Expression levels } & \multicolumn{2}{|c|}{$\mathrm{p} 53, \mathrm{n}(\%)$} & \multirow[b]{2}{*}{ P-value } & \multicolumn{2}{|c|}{ c-Myc, n (\%) } & \multirow[b]{2}{*}{ P-value } & \multicolumn{2}{|c|}{ MDM2, n (\%) } & \multirow[b]{2}{*}{ P-value } \\
\hline & & High & Low & & High & Low & & High & Low & \\
\hline \multirow[t]{2}{*}{ c-Myc } & High & $27(75.0)$ & $9(25.0)$ & 0.27 & & & & & & \\
\hline & Low & $40(62.5)$ & $24(37.5)$ & & & & & & & \\
\hline \multirow[t]{2}{*}{ MDM2 } & High & $2(66.7)$ & $1(33.3)$ & 0.99 & $2(66.7)$ & $1(33.3)$ & 0.29 & & & \\
\hline & Low & $34(35.0)$ & $36(65.0)$ & & $34(35.0)$ & $36(65.0)$ & & & & \\
\hline \multirow[t]{2}{*}{ FBXW7 } & High & $33(62.3)$ & $20(37.7)$ & 0.30 & $25(47.2)$ & $28(52.8)$ & $0.02^{\mathrm{a}}$ & $2(3.8)$ & $51(96.2)$ & 0.99 \\
\hline & Low & $34(72.3)$ & $13(27.7)$ & & $11(23.4)$ & $36(76.6)$ & & $1(2.1)$ & 46 (97.9) & \\
\hline
\end{tabular}

${ }^{\mathrm{a} P}<0.02$. FBXW7, F-box and WD repeat domain-containing 7.
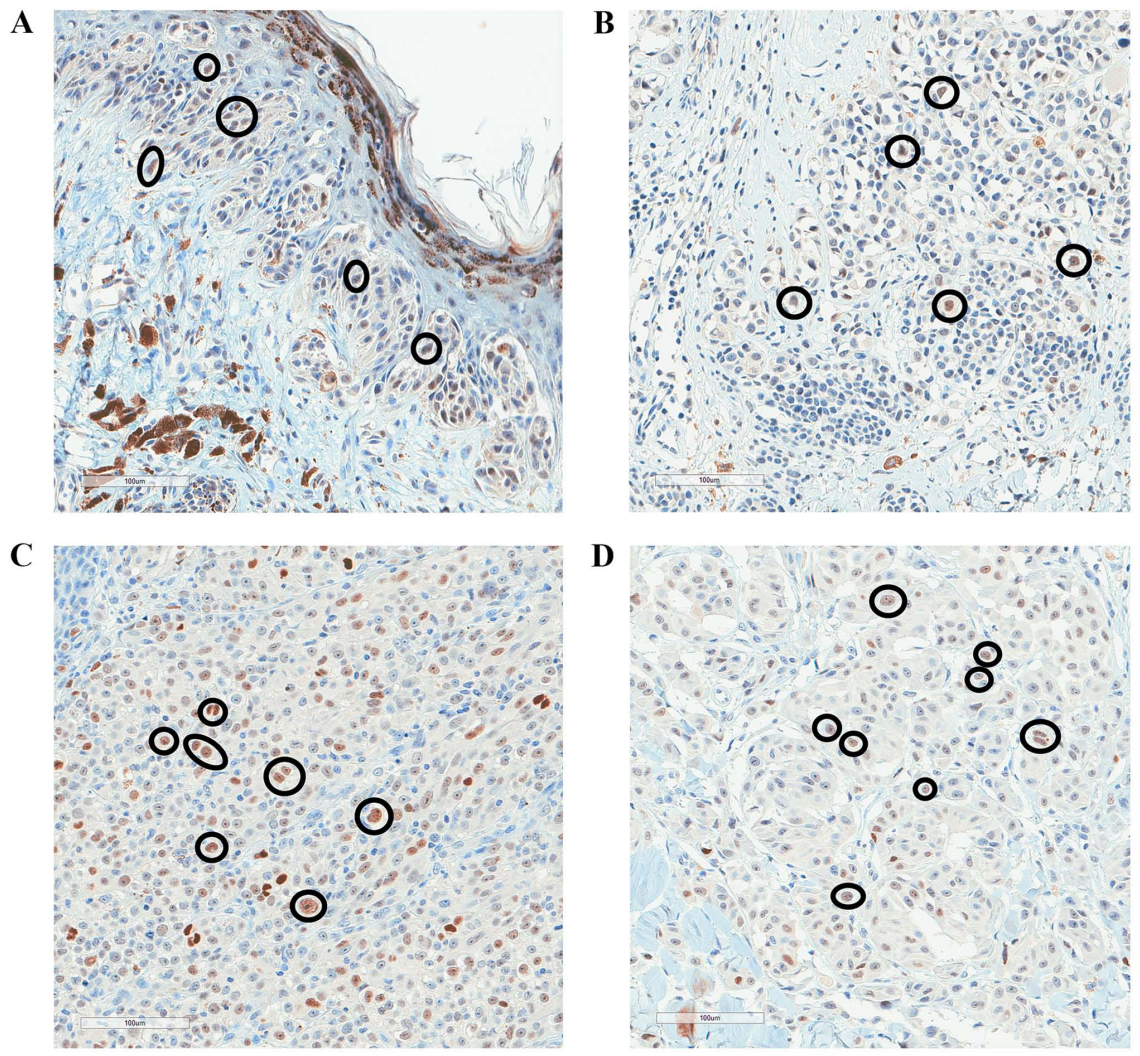

Figure 6. MDM2 protein expression in cutaneous melanoma. Representative images of (A) weak MDM2 immunostaining in pT1 melanoma and (B) in pT2 melanoma, (C) moderate MDM2 immunostaining in pT3 melanoma and (D) weak MDM2immunostaining in pT4 melanoma. Marked areas indicate MDM2 staining in malignant melanocytes. Magnification, x100. pT, pathological tumor stage.

tumor formation $(5,42)$. FBW7 $\alpha$ promotes ubiquitination of Myc in proteasomes, whereas FBW7 $\gamma$ ubiquitinates Myc in the nucleus and thus suppresses the ability of Myc to promote cell growth (41,43-46). Therefore, a decrease in FBXW7 expression results in increased c-Myc expression (10).

In the present study, 17 cases of stage pT 2 melanoma, 17 cases of stage pT3 melanoma and 17 cases of stage pT4 melanoma were examined, and low c-Myc protein expression was detected in 12 cases (70.6\%) in each group. According to a comparison of these groups with melanoma in situ and stage pT1 melanoma, the changes in c-Myc protein expression were not statistically significant. In addition, there was a strong direct association observed between the changes in
FBXW7 and c-Myc expression with a decrease in FBXW7 expression, and a decrease in c-Myc expression was also observed. These results differ from those of previously published studies $(41,45,47)$. The results of the present study may be influenced by the sample size. In addition, melanoma is a heterogeneous tumor and its development and progression is affected by the interaction of multiple genes and various signaling pathways (48). In some types of cancer, c-Myc may acquire loss-of-function mutations, while in the majority of cases, c-Myc expression is upregulated (49-52). In both cases, altered c-Myc expression results in tumor formation through disrupted transcription, translation or differentiation $(42,49)$. 
Table VI. Univariate Cox regression analysis of protein expression and clinicopathological variables predicting the survival of patients with cutaneous melanoma.

\begin{tabular}{llc}
\hline Variables & HR (95\% CI) & P-value \\
\hline Sex, males vs. females & $2.01(0.56-7.22)$ & 0.29 \\
Age, $\leq 58$ vs. >58 years & $1.16(0.39-3.49)$ & 0.79 \\
pT stage, pT1/pT2 vs. pT3/pT4 & $5.60(1.24-25.2)$ & $0.03^{\text {a }}$ \\
Morphology, superficial & $2.48(0.83-7.43)$ & 0.10 \\
spreading vs. other & & \\
Ulceration, absent vs. present & $2.79(0.95-8.08)$ & 0.06 \\
Site, sun-protected vs. sun-exposed & $0.57(0.16-2.11)$ & 0.40 \\
p53 expression, low vs. high & $2.48(0.83-7.43)$ & 0.10 \\
c-Myc expression, low vs. high & $0.36(0.08-1.63)$ & 0.19 \\
FBXW7 expression, low vs. high & $0.16(0.02-1.23)$ & 0.08 \\
\hline
\end{tabular}

${ }^{\mathrm{a}} \mathrm{P}<0.05$. HR, hazard ratio; CI, confidence interval; pT, pathological tumor; FBXW7, F-box and WD repeat domain-containing 7.

One of the most important regulators of FBXW7 is p53; p53 is a major tumor suppressor protein and is frequently mutated in several types of cancer, such as breast cancer, bone and soft tissue sarcoma, brain tumor, adrenocortical carcinoma, leukemia, stomach cancer and colorectal cancer (12-17). Previous studies have demonstrated that FBXW7 is a p53-dependent tumor suppressor gene involved in tumor development $(10,11)$. Additionally, studies have revealed that FBXW7 expression may be restored via targeting the p53 signaling pathway $(10,11)$. The increased expression levels of wild-type p53 have been previously demonstrated in melanoma (53). However, considering the malignant nature and resistance to treatment in cases of melanoma $(54,55)$, p53 does not appear to be effective as a tumor suppressor in melanoma. Although the mechanisms are not yet fully understood, certain p53 targets have been shown to be downregulated $(56,57)$.

Increased expression levels of the MDM2 oncoprotein have been reported in several types of human cancer, including sarcoma, glioma, hematologic malignancies, melanoma and carcinoma, carrying the wild-type p53 allele $(35,58)$. High levels of MDM2 are associated with a worse prognosis in several types of cancer, such as sarcoma, glioma and pediatric acute lymphoblastic leukemia $(58,59)$. Malignant melanoma is characterized by increased MDM2 expression (60). Rajabi et al (61) revealed that there was an association between MDM2 expression with tumor thickness and invasion in primary cutaneous malignant melanoma. In $50 \%$ of melanoma cases, strong MDM 2 expression is detected, leading to enhanced degradation of $\mathrm{p} 53$, and thus resulting in tumor cell proliferation $(56,60,62)$.

In the present study, upregulated p53 expression was observed in primary and invasive melanoma. In cases of melanoma with a thickness $>1 \mathrm{~mm}$, p53 expression was increased compared with in non-invasive tumors, whereas FBXW7 expression decreased in advanced melanoma. Previous studies have demonstrated that the first exon of FBXW7 has a p53 binding site $(11,63)$. Additionally,
Table VII. Multivariate Cox regression analysis of protein expression and clinicopathological variables predicting the survival of patients with cutaneous melanoma.

\begin{tabular}{llc}
\hline Variables & HR (95\% CI) & P-value \\
\hline Sex, males vs. females & $1.47(0.31-7.07)$ & 0.48 \\
Age, $\leq 58$ vs. >58 years & $0.69(0.13-3.55)$ & 0.66 \\
pT stage, pT1/pT2 vs. pT3/pT4 & $3.13(0.38-25.7)$ & 0.29 \\
Morphology, superficial & $1.37(0.28-6.60)$ & 0.69 \\
spreading vs. other & & \\
Ulceration, absent vs. present & $2.33(0.60-9.09)$ & 0.23 \\
Site, sun-protected vs. sun-exposed & $0.42(0.09-1.98)$ & 0.27 \\
p53 expression, low vs. high & $0.65(0.16-2.70)$ & 0.55 \\
c-Myc expression, low vs. high & $0.35(0.07-1.72)$ & 0.19 \\
FBXW7 expression, low vs. high & $0.65(0.05-9.12)$ & 0.75 \\
\hline
\end{tabular}

HR, hazard ratio; CI, confidence interval; pT, pathological tumor; FBXW7, F-box and WD repeat domain-containing 7.

decreased FBXW7 expression following genotoxic stress may be activated by p53 $(6,42)$. However, in the present study, there was no statistically significant association between p53 expression and the changes in FBXW7 expression.

p53 and MDM2 interact and form a negative autoregulatory loop in which elevated p53 transcriptional levels activate MDM2, which in turn decreases the levels of p53 $(15,30,36)$. The present study revealed that there was a decrease in MDM2 expression in almost all cases assessed (97\%). In contrast to published studies $(60-62,64)$, the results of the present study did not identify a significant association between MDM2 expression and melanoma invasion, and there was no association between the decrease in MDM2 expression and p53 expression.

The main limitation of the present study consists in a relatively small number of subjects in the analyzed groups, assembled according to the stage of melanoma by depth. The sample size may have influenced the results obtained and the assessment of the effect of low FBXW7 protein expression on patient survival. Future studies should continue to analyze the expression levels of E3 ubiquitin ligases in melanoma tissues, since it is important to identify new potential targets for the treatment of melanoma, as well as to evaluate their prognostic significance. Future studies should investigate the expression levels of E3 ligases and their substrates at the mRNA level, as well as other genes involved in the development of melanoma, and should evaluate their interactions, their changes in expression associated with clinical characteristics and their prognostic significance.

In conclusion, the present study demonstrated that FBXW7 exhibited the most statistically significant prognostic value and associations with advanced melanoma. As most of the FBXW7 substrates are oncoproteins, their degradation by FBXW7 may underlie the mechanism by which decreased FBXW7 expression results in tumor progression and may highlight these proteins as potential targets for the treatment of melanoma. 


\section{Acknowledgements}

Not applicable.

\section{Funding}

The present study was funded by the National Cancer Institute (grant no. ESFA Nr.09.3.3-V-711-01-0001) and the project 'Development of doctoral studies' realization according to the 2014-2020 European Union Funds Programme of Investment Activity, priority 9 'Education of society and increasing of human source potential' (grant no. ESFA-09.3.3-V-711) and 'Support for scientific research by scientists and other researchers'.

\section{Availability of data and materials}

The datasets used and/or analyzed during the current study are available from the corresponding author on reasonable request.

\section{Authors' contributions}

JM selected the patients, collected the clinicopathological data, interpreted the results and prepared the manuscript. ZG was involved in drafting and revising the manuscript, and made substantial contributions to the analysis and interpretation of data. IV performed the statistical analysis, interpreted the results and created the graphs and tables. AL was involved in performing the tissue microarray and immunohistochemical analysis, drafted and revised the manuscript. JP performed the histological examination of tissue samples of melanoma and dysplastic nevi, assisted in the tissue microarray preparation and evaluated the immunohistochemical staining. All authors read and approved the final manuscript.

\section{Ethics approval and consent to participate}

The present study was approved by the Vilnius Regional Committee of Biomedical Research (approval no. 158200-16-878-387, approval date 2016-12-13, and addition no. 158200-878-PP1-05, 2017-03-17). All patients signed informed consent forms to participate in the present study (approval no. II-2016-5, 2016-12-07, version 4, and approval no. II-2016-5, 2017-02-14, version 5).

\section{Patient consent for publication}

Not applicable.

\section{Competing interests}

The authors declare that they have no competing interests.

\section{References}

1. Morrow JK, Lin HK, Sun SC and Zhang S: Targeting ubiquitination for cancer therapies. Future Med Chem 7: 2333-2350, 2015.

2. Ma J, Guo W and Li C: Ubiquitination in melanoma pathogenesis and treatment. Cancer Med 6: 1362-1377, 2017.

3. Aydin IT, Melamed RD, Adams SJ, Castillo-Martin M, Demir A Bryk D, Brunner G, Cordon-Cardo C, Osman I, Rabadan R, et al FBXW7 mutations in melanoma and a new therapeutic paradigm. J Natl Cancer Inst 106: dju107, 2014.
4. Xie CM, Wei W and Sun Y: Role of SKP1-CUL1-F-box-protein (SCF) E3 ubiquitin ligases in skin cancer. J Genet Genomics 40: 97-106, 2013.

5. Welcker M and Clurman BE: FBW7 ubiquitin ligase: A tumour suppressor at the crossroads of cell division, growth and differentiation. Nat Rev Cancer 8: 83-93, 2008.

6. Wang Z, Inuzuka H, Zhong J, Wan L, Fukushima H, Sarkar FH and Wei W: Tumor suppressor functions of FBW7 in cancer development and progression. FEBS Lett 586: 1409-1418, 2012.

7. Huang HL, Weng HY, Wang LQ, Yu CH, Huang QJ, Zhao PP, Wen JZ, Zhou H and Qu LH: Triggering Fbw7-mediated proteasomal degradation of c-Myc by oridonin induces cell growth inhibition and apoptosis. Mol Cancer Ther 11: 1155-1165, 2012.

8. Liu H, Wang K, Fu H and Song J: Low expression of the ubiquitin ligase FBXW7 correlates with poor prognosis of patients with colorectal cancer. Int J Clin Exp Pathol 11: 413-419, 2018.

9. Cheng Y, Chen G, Martinka M, Ho V and Li G: Prognostic significance of Fbw7 in human melanoma and its role in cell migration. J Invest Dermatol 133: 1794-1802, 2013.

10. Wang L, Ye X, Liu Y, Wei W and Wang Z: Aberrant regulation of FBW7 in cancer. Oncotarget 5: 2000-2015, 2014.

11. Mao JH, Perez-Losada J, Wu D, Delrosario R, Tsunematsu R, Nakayama KI, Brown K, Bryson S and Balmain A: Fbxw7/Cdc4 is a p53-dependent, haploinsufficient tumour suppressor gene. Nature 432: 775-779, 2004

12. Pei D, Zhang Y and Zheng J: Regulation of p53: A collaboration between Mdm2 and Mdmx. Oncotarget 3: 228-235, 2012.

13. Madan E, Gogna R, Bhatt M, Pati U, Kuppusamy P and Mahdi AA: Regulation of glucose metabolism by p53: Emerging new roles for the tumor suppressor. Oncotarget 2: 948-957, 2011.

14. Muller PAJ and Vousden KH: p53 mutations in cancer. Nat Cell Biol 15: 2-8, 2013.

15. Wade M, Li Y and Wahl G: MDM2, MDMX and p53 in oncogenesis and cancer therapy. Nat Rev Cancer 13: 83-96, 2013.

16. Olivier M, Goldgar DE, Sodha N, Ohgaki H, Kleihues P, Hainaut P and Eeles RA: Li-Fraumeni and related syndromes: Correlation between tumor type, family structure, and TP53 genotype. Cancer Res 63: 6643-6650, 2003.

17. Birch JM, Alston RD, McNally RJ, Evans DG, Kelsey AM, Harris M, Eden OB and Varley JM: Relative frequency and morphology of cancers in carriers of germline TP53 mutations. Oncogene 20: 4621-4628, 2001.

18. Felsher DW and Bishop JM: Reversible tumorigenesis by MYC in hematopoietic lineages. Mol Cell 4: 199-207, 1999.

19. Marinkovic D, Marinkovic T, Mahr B, Hess J and Wirth T: Reversible lymphomagenesis in conditionally c-MYC expressing mice. Int J Cancer 110: 336-342, 2004.

20. Jain M, Arvanitis C, Chu K, Dewey W, Leonhardt E, Trinh M, Sundberg CD, Bishop JM and Felsher DW: Sustained loss of a neoplastic phenotype by brief inactivation of MYC. Science 297: 102-104, 2002.

21. Gabay M, Li Y and Felsher DW: MYC activation is a hallmark of cancer initiation and maintenance. Cold Spring Harb Perspect Med 4: 1-14, 2014.

22. Shachaf CM, Kopelman AM, Arvanitis C, Karlsson A, Beer S, Mandl S, Bachmann MH, Borowsky AD, Ruebner B, Cardiff RD, et al: MYC inactivation uncovers pluripotent differentiation and tumour dormancy in hepatocellular cancer. Nature 431: 1112-1117, 2004.

23. Sato M, Rodriguez-Barrueco R, Yu J, Do C, Silva JM and Gautier J: MYC is a critical target of FBXW7. Oncotarget 6: 3292-3305, 2015.

24. Meyer N and Penn LZ: Reflecting on 25 years with MYC. Nat Rev Cancer 8: 976-990, 2008.

25. Ross DA and Wilson GD: Expression of c-myc oncoprotein represents a new prognostic marker in cutaneous melanoma. $\mathrm{Br}$ J Surg 85: 46-51, 1998.

26. Greulich KM, Utikal J, Peter RU and Krähn G: c-MYC and nodular malignant melanoma. A case report. Cancer 89: 97-103, 2000.

27. Kraehn GM, Utikal J, Udart M, Greulich KM, Bezold G, Kaskel P, Leiter U and Peter RU: Extra c-myc oncogene copies in high risk cutaneous malignant melanoma and melanoma metastases. Br J Cancer 84: 72-79, 2001.

28. Kanzler MH and Mraz-Gernhard S: Primary cutaneous malignant melanoma and its precursor lesions: Diagnostic and therapeutic overview. J Am Acad Dermatol 45: 260-276, 2001.

29. Lin X, Sun R, Zhao X, Zhu D, Zhao X, Gu Q, Dong X, Zhang D, Zhang Y, Li Y, et al: C-myc overexpression drives melanoma metastasis by promoting vasculogenic mimicry via c-myc/snail/Bax signaling. J Mol Med (Berl) 95: 53-67, 2017. 
30. Nag S, Zhang X, Srivenugopal KS, Wang MH, Wang W and Zhang R: Targeting MDM2-p53 interaction for cancer therapy: Are we there yet? Curr Med Chem 21: 553-574, 2014.

31. Freedman DA, Wu L and Levine AJ: Functions of the MDM2 oncoprotein. Cell Mol Life Sci 55: 96-107, 1999.

32. Momand J, Wu HH and Dasgupta G: MDM2 - master regulator of the p53 tumor suppressor protein. Gene 242: 15-29, 2000.

33. Oliner JD, Pietenpol JA, Thiagalingam S, Gyuris J, Kinzler KW and Vogelstein B: Oncoprotein MDM2 conceals the activation domain of tumour suppressor p53. Nature 362: 857-860, 1993.

34. Momand J, Zambetti GP, Olson DC, George D and Levine AJ: The mdm-2 oncogene product forms a complex with the p53 protein and inhibits p53-mediated transactivation. Cell 69: $1237-1245,1992$.

35. Li Q and Lozano G: Molecular pathways: Targeting Mdm2 and Mdm4 in cancer therapy. Clin Cancer Res 19: 34-41, 2013.

36. Vassilev LT: MDM2 inhibitors for cancer therapy. Trends Mol Med 13: 23-31, 2007.

37. Amin MB, Edge S, Greene F, Byrd DR, Brookland RK, Washington MK, Gershenwald JE, Compton CC, Hess KR, Sullivan DC, et al (eds): AJCC Cancer Staging Manual, 8th edition. Springer, 2017.

38. Cheng Y and Li G: Role of the ubiquitin ligase Fbw7 in cancer progression. Cancer Metastasis Rev 31: 75-87, 2012.

39. Busino L, Millman SE, Scotto L, Kyratsous CA, Basrur V, O'Connor O, Hoffmann A, Elenitoba-Johnson KS and Pagano M: Fbxw $7 \alpha$ - and GSK3-mediated degradation of p100 is a prosurvival mechanism in multiple myeloma. Nat Cell Biol 14: 375-385, 2012

40. Min SH, Lau AW, Lee TH, Inuzuka H, Wei S, Huang P, Shaik S, Lee DY, Finn G, Balastik M, et al: Negative regulation of the stability and tumor suppressor function of Fbw 7 by the Pin 1 prolyl isomerase. Mol Cell 46: 771-783, 2012.

41. Yada M, Hatakeyama S, Kamura T, Nishiyama M, Tsunematsu R, Imaki H, Ishida N, Okumura F, Nakayama K and Nakayama KI: Phosphorylation-dependent degradation of c-Myc is mediated by the F-box protein Fbw7. EMBO J 23: 2116-2125, 2004.

42. Davis RJ, Welcker M and Clurman BE: Tumor suppression by the Fbw7 ubiquitin ligase: Mechanisms and opportunities. Cancer Cell 26: 455-464, 2014

43. Bonetti P, Davoli T, Sironi C, Amati B, Pelicci PG and Colombo E: Nucleophosmin and its AML-associated mutant regulate c-Myc turnover through Fbw7 $\gamma$. J Cell Biol 182: 19-26, 2008.

44. Grim JE, Gustafson MP, Hirata RK, Hagar AC, Swanger J, Welcker M, Hwang HC, Ericsson J, Russell DW and Clurman BE: Isoform- and cell cycle-dependent substrate degradation by the Fbw7 ubiquitin ligase. J Cell Biol 181: 913-920, 2008.

45. Welcker M, Orian A, Grim JE, Eisenman RN and Clurman BE: A nucleolar isoform of the Fbw7 ubiquitin ligase regulates c-Myc and cell size. Curr Biol 14: 1852-1857, 2004.

46. Welcker M, Orian A, Jin J, Grim JE, Harper JW, Eisenman RN and Clurman BE: The Fbw7 tumor suppressor regulates glycogen synthase kinase 3 phosphorylation-dependent c-Myc protein degradation. Proc Natl Acad Sci USA 101: 9085-9090, 2004.

47. Reavie L, Buckley SM, Loizou E, Takeishi S, Aranda-Orgilles B, Ndiaye-Lobry D, et al: Regulation of c-Myc ubiquitination controls CML initiation and progression. Cancer Cell 23: 362-375, 2013.

48. Niezgoda A, Niezgoda P and Czajkowski R: Novel approaches to treatment of advanced melanoma: A review on targeted therapy and immunotherapy. Biomed Res Int 2015: 85138, 2015.
49. Kalkat M, De Melo J, Hickman KA, Lourenco C, Redel C, Resetca D, Tamachi A, Tu WB and Penn LZ: MYC deregulation in primary human cancers. Genes (Basel) 8: 2-30, 2017.

50. Cancer Genome Atlas Network: Comprehensive molecular portraits of human breast tumors. Nature 490: 61-70, 2012.

51. Witkiewicz AK, McMillan EA, Balaji U, Baek G, Lin WC, Mansour J, Mollaee M, Wagner KU, Koduru P, Yopp A, et al: Whole-exome sequencing of pancreatic cancer defines genetic diversity and therapeutic targets. Nat Commun 6: 6744, 2015.

52. Cancer Genome Atlas Research Network: Integrated genomic analyses of ovarian carcinoma. Nature 474: 609-615, 2011.

53. Houben R, Hesbacher S, Schmid CP, Kauczok CS, Flohr U, Haferkamp S, Müller CS, Schrama D, Wischhusen J and Becker JC: High-level expression of wild-type p53 in melanoma cells is frequently associated with inactivity in p53 reporter gene assays. PLoS One 6: e22096, 2011.

54. Winder M and Virós A: Mechanisms of drug resistance in melanoma. Handb Exp Pharmacol 249: 91-108, 2018.

55. Webster MR, Fane ME, Alicea GM, Basu S, Kossenkov AV, Marino GE, Douglass SM, Kaur A, Ecker BL, Gnanapradeepan K, et al: Paradoxical role for wild-type p53 in driving therapy resistance in melanoma. Mol Cell 77: 633-644. e5, 2020.

56. Soengas MS, Capodieci P, Polsky D, Mora J, Esteller M, Opitz-Araya X, McCombie R, Herman JG, Gerald WL, Lazebnik YA, et al: Inactivation of the apoptosis effector Apaf-1 in malignant melanoma. Nature 409: 207-211, 2001.

57. Karst AM, Dai DL, Martinka M and Li G: PUMA expression is significantly reduced in human cutaneous melanomas. Oncogene 24: 1111-1116, 2005

58. Onel $\mathrm{K}$ and Cordon-Cardo C: MDM2 and prognosis. Mol Cancer Res 2: 1-8, 2004.

59. Sun Y: E3 ubiquitin ligases as cancer targets and biomarkers. Neoplasia 8: 645-654, 2006.

60. Polsky D, Bastian B, Hazan C, Melzer K, Pack J, Houghton A, Busam K, Cordon-Cardo C and Osman I: HDM2 protein overexpression, but not gene amplification, is related to tumorigenesis of cutaneous melanoma. Cancer Res 61: 7642-7646, 2001.

61. Rajabi P, Karimian P and Heidarpour M: The relationship between MDM2 expression and tumor thickness and invasion in primary cutaneous malignant melanoma. J Res Med Sci 17: 452-455, 2012

62. Polsky D, Melzer K, Hazan C, Panageas KS, Busam K, Drobnjak M, Kamino H, Spira JG, Kopf AW, Houghton A, et al: HDM2 protein overexpression and prognosis in primary malignant melanoma. J Natl Cancer Inst 94: 1803-1806, 2002.

63. Kimura T, Gotoh M, Nakamura Y and Arakawa H: hCDC4b, a regulator of cyclin $\mathrm{E}$, as a direct transcriptional target of $\mathrm{p} 53$. Cancer Sci 94: 431-436, 2003.

64. Muthusamy V, Hobbs C, Nogueira C, Cordon-Cardo C, McKee PH, Chin L and Bosenberg MW: Amplification of CDK4 and MDM2 in malignant melanoma. Genes Chromosomes Cancer 45: 447-454, 2006.

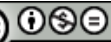

This work is licensed under a Creative Commons Attribution-NonCommercial-NoDerivatives 4.0 International (CC BY-NC-ND 4.0) License. 